\title{
Rates of Formal Diagnosis in People Screened Positive for Dementia in Primary Care: Results of the DelpHi-Trial
}

\author{
Tilly Eichler ${ }^{\mathrm{a}, *}$, Jochen René Thyrian ${ }^{\mathrm{a}}$, Johannes Hertel ${ }^{\mathrm{a}}$, Leonore Köhler ${ }^{\mathrm{a}}$, Diana Wucherer ${ }^{\mathrm{a}}$, \\ Adina Dreier $^{\mathrm{b}}$, Bernhard Michalowsky ${ }^{\mathrm{a}}$, Stefan Teipel ${ }^{\mathrm{c}, \mathrm{d}}$ and Wolfgang Hoffmann ${ }^{\mathrm{a}, \mathrm{b}}$ \\ ${ }^{a}$ German Center for Neurodegenerative Diseases (DZNE), Rostock/Greifswald, Greifswald, Germany \\ ${ }^{\mathrm{b}}$ Institute for Community Medicine, Section Epidemiology of Health Care and Community Health, \\ University Medicine Greifswald, Greifswald, Germany \\ ${ }^{\mathrm{c}}$ German Center for Neurodegenerative Diseases (DZNE), Rostock/Greifswald, Rostock, Germany \\ ${ }^{\mathrm{d}}$ Department of Psychosomatic Medicine, Rostock University Medical Center, Rostock, Germany
}

Accepted 8 April 2014

\begin{abstract}
.
Background: Primary data about rates of formal diagnosis of dementia in the German primary care sector are widely lacking. Objectives: Main objectives are to analyze the rate of syndrome diagnosis in primary care patients who screened positive for dementia, the distribution of differential diagnoses, and factors associated with undiagnosed dementia.

Methods: DelpHi-MV (Dementia: life- and person-centered help in Mecklenburg-Western Pomerania) is an ongoing general practitioner (GP)-based, randomized, controlled intervention trial. A total of 4,064 patients ( $\geq 70$ years, living at home) recruited from 108 participating GP practices were screened for dementia (DemTect <9). Of 692 eligible patients $(17 \%)$, a total of 406 subjects $(59 \%)$ provided informed consent. Present analyses are based on the data of 243 patients with complete baseline assessment on January 1, 2014 (preliminary data). Formal diagnoses were retrieved from the medical records of the treating GPs. A conditional fixed effect regression analysis was performed to analyze factors associated with undiagnosed dementia.

Results: A total of $40 \%$ of patients who screened positive for dementia had been formally diagnosed with dementia. Unspecified dementia was diagnosed in 53\%, vascular dementia in 24\%, and Alzheimer's disease in 19\% of these patients. Undiagnosed dementia was significantly associated with a higher mean score in the Mini-Mental State Examination (odds ratio, 1.11; $p<0.01$, 95\% confidence interval 1.04-1.18).

Conclusions: The diagnosis rate of dementia in German primary care (40\%) is well within the range of the international data $(20-50 \%)$. The results emphasize the need for action to enhance recognition and differential diagnosis of dementia.
\end{abstract}

Keywords: Dementia, differential diagnosis, early diagnosis, primary health care, screening

ClinicalTrials.gov Identifier: NCT01401582

\section{INTRODUCTION}

*Correspondence to: Dr. Tilly Eichler, German Center for Neurodegenerative Diseases (DZNE), Rostock/Greifswald, Ellernholzstrasse 1-2, Greifswald D-17487, Germany. Tel.: +493834 86 7591; Fax: +49 383486 19551; E-mail: tilly.eichler@dzne.de.
The prevalence of dementia will approximately double worldwide within the next 20 years [1]. Although causal treatment is not yet available, diagnosing dementia at an early stage is essential for providing 
timely access to information, evidence-based treatment, care, and support [2]. An early diagnosis allows people with dementia (PWD) and their caregivers to make decisions concerning their future while they still possess relevant cognitive capacities [3]. Surveys have shown that a large majority of the participants would prefer to be diagnosed early and to be properly informed about their diagnosis $[4,5]$.

Moreover, early psychosocial and pharmaceutical interventions and effective care management can have a positive impact on cognitive functions, activities of daily living, quality of care, and delaying institutionalization [3, 6-8]. According to economic health models, the costs of early diagnosis and therapy of dementia are outweighed by the savings from benefits, such as delayed institutionalization $[2,9,10]$.

In the majority of health care systems, dementia is considerably underdiagnosed. A high percentage of PWD does not receive a formal diagnosis of dementia or are diagnosed at an advanced disease stage. Even in high income countries, 50-80\% of PWD do not receive a formal diagnosis in primary care facilities $[2,7,11$, 12]. Mitchell et al. [13] found in a meta-analysis that general practitioners (GPs) were able to identify $73 \%$ of PWD by clinical judgment but made correct annotations in the medical record only in $38 \%$ of cases. According to Löppönen and colleagues [14], undiagnosed dementia is associated with milder forms of dementia, male sex, living at home, better coping with instrumental activities of daily living, and depression.

German evidence-based guidelines for diagnosis and treatment of dementia $[15,16]$ emphasize the importance of a timely diagnosis of dementia including an etiological differential diagnosis in order to initiate specific treatment and care as well as to identify and treat reversible causes of cognitive disorders, such as depression or endocrinopathy. A recent analysis of secondary data of people diagnosed with dementia in ambulatory medical care facilities have shown that even in patients treated by dementia specialists (neurologists/psychiatrists), a considerable lack of differential diagnoses exists; $46 \%$ of the patients are diagnosed with unspecified dementia (ICD-10 code F03) [17]. The analyses of secondary data have presented methodological problems. To the best of our knowledge, there are no primary data available concerning the rates of syndrome or differential diagnosis in people with cognitive decline in the German primary care sector. Therefore, the primary objectives of the present study are to determine (1) the rate of a syndrome diagnosis in primary care patients who screened positive for dementia, (2) the distribution of differ- ential diagnoses and (3) the factors associated with undiagnosed dementia.

\section{MATERIAL AND METHODS}

Study design

The present cross-sectional analyses are based on data derived from the ongoing GP-based, randomized, controlled intervention trial DelpHi-MV (Dementia: life- and person-centered help in MecklenburgWestern Pomerania) [18]. The eligible patients $(\geq 70$ years, living at home) in participating GP practices are screened by the practice staff for dementia using DemTect [19], which is a widely used dementia screening test in general practices in Germany [20]. The patients who meet the inclusion criteria for the DelpHitrial (DemTect <9) are informed by their GPs about the study, are invited to participate, and are asked to provide written informed consent. If the patient names a caregiver, he or she is asked to participate in the study. When the patient is unable to give written informed consent, his or her legal representative is asked to sign the consent form on his or her behalf (as approved by the Ethical Committee of the Chamber of Physicians of Mecklenburg-Western Pomerania, registry number BB 20/11). The enrollment into the main study started on January 1, 2012. The participants and their caregivers are assigned to an intervention or a control group, depending on whether the treating GP practice was randomized to either the control or intervention group. In both groups, identical, standardized, computer-assisted baseline assessments are conducted in face-to-face interviews in the participants' homes. Because of the amount of information assessed and the limited cognitive capacities of the participants, the interviewers split the assessment into 2 to 4 visits. After the baseline assessment, the intervention group receives the "DelpHi-Intervention" whereas the control group receives "care as usual" (a detailed description of the DelpHi-trial [18] and the "DelphiIntervention" [21] are provided elsewhere).

\section{Sample}

Of the 4,064 patients ( $\geq 70$ years, living at home) screened for dementia in 108 participating GP practices, 629 patients $(17 \%)$ were eligible for the DelpHi-trial (DemTect <9). Of these, 406 patients (59\%) agreed to participate in the DelpHi-trial. The present analyses are based on the data of 243 patients with complete baseline assessment regarding relevant 
variables on January 1, 2014 (preliminary data). Ninety participants did not start or finish the baseline assessment at the time of the analyses. Fifty-eight patients dropped out of the analyses due to withdrawal of informed consent $(n=31)$; death $(n=20)$; relocation $(n=3)$; and other reasons $(n=4)$. There were no significant differences between patients included and those who dropped-out regarding the variables DemTect score, age, and gender (see Supplementary Table 1).

Fifteen patients were excluded because the psychometric instruments could not be utilized (patients were not able to answer the questions due to the severity of dementia or patients refused to answer for other reasons). Patients included into the analyses had a significantly higher DemTect score $(M=5.84$, $\mathrm{SD}=2.02$ ) than patients that were excluded because of missing data $(\mathrm{M}=3.73, \mathrm{SD}=2.34$; Welch's- $t$-test: $\mathrm{t}$ $(15.50)=3.41 ; p<0.01)$. Regarding the variables age, gender, and formal diagnosis of dementia we found no significant differences (see Supplementary Table 2).

\section{Procedures and instruments}

For sample description, we used the variables age, gender, living situation (alone/not alone), cognitive impairment, depression, and functional status. The severity of cognitive impairment was assessed using the German version of Mini-Mental State Examination (MMSE) [22]. For analyses, we used the total score as well as a categorization that indicates "no cognitive impairment" (score, 27-30), "mild" (score, 20-26), "moderate" (score, 10-19), and "severe cognitive impairment" (score, 0-9). Depression was assessed using the score of the Geriatric Depression Scale [23, 24] as dichotomized variable ("no depression": score, 0-5; "depression": score, 6-15). The functional status was assessed using the Bayer Activities of Daily Living Scale $[25,26]$, which yields a mean score between 1 to 10 , where 1 indicates the lowest possible impairment and 10 indicates the highest possible impairment. The medical diagnoses (ICD-10 codes: F00, F01, F02, F03, G30, and G31), including the exact date of the initial diagnosis, were retrieved from the patients' medical records with the permission of the treating GPs. The diagnoses assigned on the screening day or subsequently thereafter were excluded from the present analyses.

\section{Statistical analyses}

We summarized the variables that describe the sample using descriptive statistics. We analyzed the difference in the severity of cognitive impairment between patients with and without formal diagnosis of dementia using Welch's $t$-test (robust to unequal variances). Fisher's exact test was used to test if the diagnosis of dementia is stochastically independent of categorized cognitive impairment. To identify the factors associated with undiagnosed dementia, we fitted a logistic regression model including cognitive impairment as explanatory variable and age, gender, living situation, depression, and functional status as covariates. Because DelpHi-MV is a cluster-randomized trial, we considered the dependency of data from participants who belong to the same cluster (i.e., the same treating GP). Therefore, we applied a conditional (fixed effect) logistic regression model, which offers consistent estimates in case of clustered data [27, 28]. Before running the final regression model, we checked for non-linear relations using the multivariate fractional polynomial procedure [29]. We found no indication for non-linear relations. The chosen estimation procedure excluded 58 observations because of the invariance in the outcome variable in certain clusters (that is, all or none of the patients treated by the same GP are formally diagnosed with dementia). We found no significant differences between the included and the excluded cases regarding the analyzed variables (see Supplementary Table 3). The final regression analysis was performed on the remaining 185 patients assigned to 26 clusters (clusters are unbalanced). Standard errors of the regression coefficients were estimated using the jackknife method, which allows to estimate standard errors in complex samples [30]. We performed statistical analyses using STATA/IC [31].

\section{RESULTS}

\section{Sociodemographic and clinical characteristics}

Table 1 presents the sociodemographic and clinical characteristics of the study sample.

\section{Diagnosis rates}

Of the 243 patients with positive DemTect screening in the Delphi-trial, 97 patients (40\%) had at least one formal diagnosis of dementia in their medical record before the day of screening. Documentation rates (the proportion of patients with documented formal dementia diagnoses) were $21 \%$ in patients without cognitive impairment, $42 \%$ in patients with mild cognitive impairment, $52 \%$ in patients with moderate cognitive impairment and $54 \%$ in patients with severe 
Table 1

Sociodemographic and clinical characteristics of the study sample

\begin{tabular}{|c|c|c|c|}
\hline & $\begin{array}{l}\text { Total sample } \\
(n=243)\end{array}$ & $\begin{array}{l}\text { Patients with diagnosis } \\
\qquad(n=97)\end{array}$ & $\begin{array}{l}\text { Patients without diagnosis } \\
\qquad(n=146)\end{array}$ \\
\hline Age & $79.61(5.44)$ & $79.61(5.64)$ & $79.62(5.33)$ \\
\hline Gender (female) & $148(61 \%)$ & $56(58 \%)$ & $92(63 \%)$ \\
\hline Living alone & $113(47 \%)$ & $46(47 \%)$ & $67(46 \%)$ \\
\hline Cognitive impairment (MMSE) & $22.01(5.50)$ & $20.34(5.88)$ & $23.12(4.96)$ \\
\hline Functional status (B-ADL) & $3.61(2.39)$ & $4.11(2.54)$ & $3.28(2.23)$ \\
\hline Depression (GDS) & $60(25 \%)$ & $24(25 \%)$ & $36(25 \%)$ \\
\hline
\end{tabular}

Standard deviations or percentages are in brackets. MMSE, Mini Mental State Examination, range 0-30, higher score indicates better cognitive functioning; B-ADL, Bayer Activities of Daily Living Scale, range 0-10, lower score indicates better performance; GDS, Geriatric Depression Scale, sum score $0-15$, score $\geq 6$ indicates depression.

Table 2

Severity of cognitive impairment and formal diagnosis of dementia

\begin{tabular}{lccc}
\hline & $\begin{array}{c}\text { Total sample } \\
(n=243)\end{array}$ & $\begin{array}{c}\text { Patients with diagnosis } \\
(n=97)\end{array}$ & $\begin{array}{c}\text { Patients without diagnosis } \\
(n=146)\end{array}$ \\
\hline Cognitive impairment (MMSE, total score) & $21.86(5.39)$ & $20.34(5.88)$ & $23.12(4.96)^{\mathrm{a}}$ \\
No impairment (score, 27-30) & 58 & $12(21 \%)$ & $46(79 \%)^{\mathrm{b}}$ \\
Mild impairment (score, 20-26) & 106 & $44(42 \%)$ & $62(58 \%)$ \\
Moderate impairment (score, 10-19) & 66 & $34(52 \%)$ & $32(48 \%)$ \\
Severe impairment (score, 0-9) & 13 & $7(54 \%)$ & $6(46 \%)$ \\
\hline
\end{tabular}

Standard deviations or percentages are in brackets. MMSE, Mini Mental State Examination, range 0-30, higher score indicates better cognitive functioning; ${ }^{\mathrm{a}}$ Welch's $t$-test: $\mathrm{t}(181.47)=3.84, p<0.001$; ${ }^{\mathrm{b}}$ Fisher's exact test: $p<0.01$.

Table 3

Factors associated with undiagnosed dementia

\begin{tabular}{|c|c|c|c|c|c|c|c|}
\hline & $\begin{array}{l}\text { Patients with diagnosis } \\
\qquad(n=75)\end{array}$ & $\begin{array}{l}\text { Patients without diagnosis } \\
\qquad(n=110)\end{array}$ & OR & $t$ & $p$ & $95 \% \mathrm{CI}$ & \\
\hline Age & $78.81(5.73)$ & $79.70(5.41)$ & 1.04 & 0.81 & 0.42 & 0.94 & 1.14 \\
\hline Gender (female) & $41(55 \%)$ & $67(61 \%)$ & 1.20 & 0.37 & 0.71 & 0.43 & 3.33 \\
\hline Living alone & $35(47 \%)$ & $45(41 \%)$ & 1.68 & 1.43 & 0.16 & 0.80 & 3.55 \\
\hline Cognitive impairment (MMSE) & $20.08(5.76)$ & $23.02(5.12)$ & 1.11 & 3.26 & $<0.01$ & 1.04 & 1.18 \\
\hline Functional status (B-ADL) & $3.93(2.52)$ & $3.24(2.13)$ & 0.96 & 0.40 & 0.69 & 0.79 & 1.18 \\
\hline Depression (GDS) & $16(21 \%)$ & $27(25 \%)$ & 1.46 & 1.13 & 0.27 & 0.73 & 2.92 \\
\hline
\end{tabular}

Conditional fixed effect logistic regression analysis with ( $n=185$ patients assigned to $n=26$ clusters $): \mathrm{F}(6,25)=4.06, p<0.01 ;$ Standard deviations or percentages are in brackets. OR, odds ratio, CI, confidence interval; MMSE, Mini Mental State Examination, range 0-30, higher score indicates better cognitive functioning; B-ADL, Bayer Activities of Daily Living Scale, range 0-10, lower score indicates better performance; GDS, Geriatric Depression Scale, sum score 0-15, score $\geq 6$ indicates depression.

cognitive impairment according to the MMSE score (Table 2).

\section{Differential diagnoses}

There was a noticeably high percentage of the diagnosis unspecified dementia (F03/G30), which was the exclusive diagnosis for $53 \%$ of the patients $(n=51)$ (see Fig. 1). Vascular dementia (F01) was diagnosed in $24 \%$ of the patients $(n=23)$, dementia in Alzheimer's disease (F00/G30) in $19 \%$ of the patients $(n=18)$, other degenerative diseases of the nervous system, not classified elsewhere (G31.1; G31.9) in 4\% of the patients $(n=4)$, and dementia in Parkinson's disease (F02.3) in one patient.

\section{Factors associated with undiagnosed dementia}

Univariate statistical analysis showed that formally diagnosed patients $(M=20.34, S D=5.88)$ had a significant lower MMSE score than patients not diagnosed with dementia $(\mathrm{M}=23.12, \mathrm{SD}=4.96$; Welch's $t$-test: $\mathrm{t}$ $(181.49)=3.84, p<0.001)$. The diagnosis of dementia was stochastically not independent of categorized cognitive impairment (Fisher's exact test: $p<0.01$ ) (see Table 2).

The multivariate conditional logistic regression analysis yielded the following significant model ( $\mathrm{F}$ $(6,25)=4.06, p<0.01)$ : the only factor significantly associated with undiagnosed dementia was less cognitive impairment. Each additional point in the MMSE 


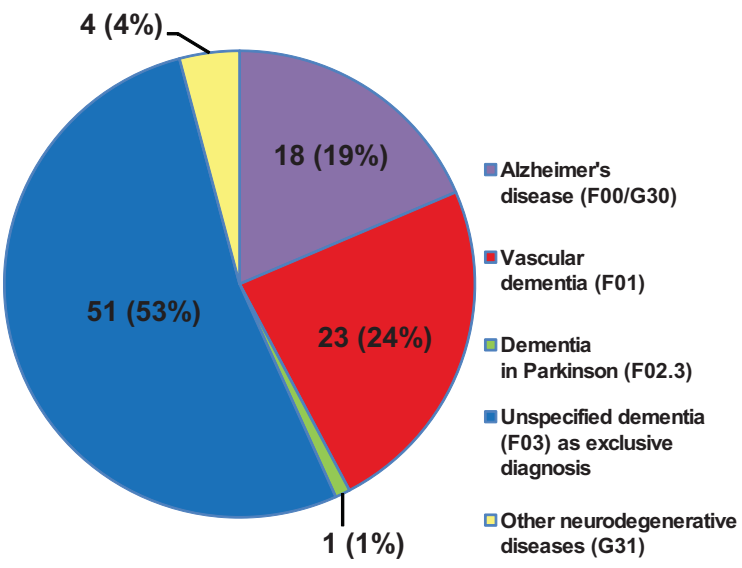

Fig. 1. Differential diagnoses of dementia in formally diagnosed primary care patients who screened positive for dementia $(n=97)$.

score indicates an $11 \%$ higher chance for undiagnosed dementia (odds ratio (OR), 1.11, $p<0.01,95 \%$ confidence interval (CI) 1.04-1.18). The results are shown in Table 3.

\section{DISCUSSION}

The present study aimed to analyze the diagnosis rate of dementia in primary care patients who screened positive for dementia, the distribution of differential diagnoses as well as the factors that are associated with undiagnosed dementia.

\section{Diagnosis rate}

Of the primary care patients who screened positively for dementia, $40 \%$ were formally diagnosed with dementia. Thus, the diagnosis rate in German primary care is well within the range of the international reference data (20-50\%) [2, 7, 11, 12]. In our sample, 58\% of patients with mild cognitive impairment, $48 \%$ of patients with moderate cognitive impairment, and $46 \%$ of patients with severe cognitive impairment remained undiagnosed. Assuming that a large proportion of these subjects have a dementia syndrome underlying their cognitive decline, not diagnosing these patients takes them the chance to timely prepare for the future progression of the disease. Without a formal diagnosis, these patients might be excluded from adequate treatment and care. Therefore, our results emphasize the need for action to enhance recognition of dementia in primary care [2].

\section{Distribution of differential diagnoses}

Regarding the distribution of differential diagnoses, we observed a noticeably high percentage of the diagnosis unspecified dementia, which was the exclusive diagnosis for $53 \%$ of the diagnosed patients. Alzheimer's disease (AD) was diagnosed in only $19 \%$ of the patients. These findings agree with the distribution of differential diagnoses found for nursing home residents with dementia [32,33]. The analyses of secondary data of patients in ambulatory medical care showed that unspecified dementia was diagnosed by GPs in $62 \%$ of patients and by specialists (neurologists/psychiatrists) in $46 \%$ of patients [17]. Based on the epidemiological data showing that 50-70\% of the patients in the age group of our subjects fulfill the clinical criteria of AD [15], a high proportion of patients diagnosed with unspecified dementia may likely have AD. GPs may not feel confident in performing the differential diagnosis [20], or they are not convinced that additional differential diagnosis is beneficial for patients with suspected AD. A prevalent notion among GPs is that causal treatment for dementia is not available. Therefore, some GPs may not feel the need to refer patients to a specialist for a differential diagnosis. According to a survey among GPs in Germany, only $31 \%$ of the respondents stated that the diagnosis of dementia was made predominantly in the context of a referral to a specialist [34]. However, German evidence-based guidelines for the diagnosis of dementia emphasize the importance of an etiological differential diagnosis to assign patients to different therapeutic options, for instance, for frontotemporal or Lewy body dementia [15] as well as to identify and treat reversible causes of cognitive disturbances, such as depression or vitamin B12 deficiency $[15,16]$. Thus, the present results underline the need to enhance the differential diagnosis of dementia.

Vascular dementia was diagnosed in $24 \%$ of the patients, this finding agrees with the epidemiologic data $(15-25 \%)$ [35]. Consistent with our results, a previous study demonstrated that a majority of GPs diagnose vascular dementia more often than $\mathrm{AD}$ [36].

\section{Factors associated with undiagnosed dementia}

Lesser cognitive impairment was the only factor that was significantly associated with undiagnosed dementia in multivariate analysis. This finding is only partially consistent with the result of a previous study [14] that showed that not only milder cognitive 
impairment was significantly associated with undiagnosed dementia, but also male sex, living at home, better coping with instrumental activities of daily living, and depression.

\section{Generalizability of the results}

The present results are consistent with previous findings. Of approximately 4,000 patients (aged 70+ years) who were screened for dementia, $17 \%$ scored positive and $59 \%$ of these patients agreed to participate in the DelpHi-trial. Twenty-four percent were not cognitively impaired according to their MMSE score. In a study involving the cognitive screening of older adults (aged 65+ years) in primary care in Seattle (USA), $18 \%$ of 524 patients were screened positive [37]. Boustani et al. [11] screened more than 3000 patients (aged 65+ years) in GP practices in Indianapolis (USA) and noted that $13 \%$ scored positive; $52 \%$ agreed to complete the diagnostic assessment. Of these, $80 \%$ were diagnosed with dementia or cognitive impairment; the remaining $20 \%$ had no cognitive impairment. In a populationbased sample of adults (aged 75+ years) in Leipzig (Germany), the prevalence of dementia according to the ICD-10 criteria was $12.4 \%$ [38].

\section{Limitations}

We observed that $24 \%$ of the patients that screened positive for dementia using DemTect were not identified as being cognitively impaired according to their MMSE score. This could imply a relatively high proportion of false positive cases. However, the sensitivity for detecting milder forms of cognitive impairment is very high for DemTect $(80-100 \%)$ [39, 40], whereas the sensitivity is relatively poor for MMSE (43-46\%) [41]. In addition, we found that $21 \%$ of patients without cognitive impairment according to the MMSE had a formal diagnosis of dementia in their patient records. This finding could support the assumption that the sensitivity of the MMSE is insufficient for detecting mild cognitive impairment. Alternatively, patients could have been misdiagnosed by their GP. A possible reason for such misdiagnoses could be the presence of reversible causes of cognitive impairment (such as depression, endocrinopathy, or delirium) at the time of diagnosis, which were mistaken as a dementia syndrome and diagnosed accordingly. Overall, DemTect might be the more favorable instrument to distinguish cognitively healthy and cognitively impaired patients. However, even when applying the criterion of the more conservative test (MMSE), more than half of the patients with mild to severe cognitive impairment remained undiagnosed.

The formal diagnoses in the medical records were not validated according to the current guidelines. Validating formal diagnoses in medical records (which was not the focus of the present study) would require a different study design. That would strengthen the results but could not be performed in routine care.

The patients that were excluded from the analysis due to missing data had a significant lower DemTect score than patients that were included into the analysis. However, there was no significant difference in the diagnosis rate of excluded and included patients. Thus, the present results should not be distorted by the exclusion of these patients.

\section{Strengths}

Despite these limitations the present study has some strong features. This is the first study to analyze primary data of community dwelling primary care patients with dementia thus the results have a high external validity. The present findings underline the importance of analyzing primary data in the context of health care research. By utilizing secondary data from health insurance companies, only formally diagnosed PWD are included in the analyses while a majority of the persons concerned is ignored.

\section{Future research}

The present results confirm that dementia is still underdiagnosed in German primary care. To include study participants into the DelpHi-trial, patients $(\geq 70$ years, living at home) are screened in the participating GP practices and followed up for five years. Additional data analysis would assess whether the screening for dementia could improve the early identification of dementia in primary care patients. However, routine screening is controversially discussed and not recommended in existing dementia guidelines because of its potential adversities, such as misdiagnosis, unnecessary examinations and treatments with side effects. The early diagnosis of dementia can be associated with anxiety, depression, fear of negative financial or social consequences, or removal of driving privileges $[3,42$, 43]. Analyzing our follow-up data will enable us to determine the impact of a dementia diagnosis on the received treatment, quality of life, caregiver burden, anxiety, and depression. 


\section{ACKNOWLEDGMENTS}

The DelpHi-trial was developed and established as a result of the input from the following experts in their respective fields (with support provided by an experienced field study team): Ines Abraham, Kerstin Albuerne, Aniela Angelow, Grit Aßmann, Vaska Böhmann, Georgia Böwing, Kathleen Dittmer, Thomas Fiß, Daniel Fredrich, Sarah Gardzella, Jana Hubert, Ulrike Kempe, Ingo Kilimann, Saskia Moll, Sabine Schmidt, Christiane Schnick, Christine Winckler and Paula Winter. We thank all of the participating patients and their general practitioners for their collaboration.

Authors' disclosures available online (http://www. j-alz.com/disclosures/view.php?id=2261).

\section{SUPPLEMENTARY MATERIAL}

The supplementary tables are available in the electronic version of this article: http://dx.doi.org/10.3233/ JAD-140354.

\section{REFERENCES}

[1] Prince M, Bryce R, Albanese E, Wimo A, Ribeiro W, Ferri CP (2013) The global prevalence of dementia: A systematic review and metaanalysis. Alzheimers Dement 9, 63-75.

[2] Prince M, Bryce R, Ferri C (2011) World Alzheimer Report 2011 - The benefits of early diagnosis and intervention, Alzheimer's Disease International, London.

[3] Borson S, Frank L, Bayley PJ, Boustani M, Dean M, Lin PJ, McCarten JR, Morris JC, Salmon DP, Schmitt FA, Stefanacci RG, Mendiondo MS, Peschin S, Hall EJ, Fillit H, Ashford JW (2013) Improving dementia care: The role of screening and detection of cognitive impairment. Alzheimers Dement $\mathbf{9}$, 151-159.

[4] Luck T, Luppa M, Sieber J, Schomerus G, Werner P, Konig HH, Riedel-Heller SG (2012) Attitudes of the German general population toward early diagnosis of dementia-results of a representative telephone survey. PLos ONE 7, e50792.

[5] Pinner G, Bouman WP (2003) Attitudes of patients with mild dementia and their carers towards disclosure of the diagnosis. Int Psychogeriatr 15, 279-288.

[6] Tinklenberg JR, Kraemer HC, Yaffe K, Ross L, Sheikh J, Ashford JW, Yesavage JA, Taylor JL (2007) Donepezil treatment and Alzheimer disease: Can the results of randomized clinical trials be applied to Alzheimer disease patients in clinical practice? Am J Geriatr Psychiatry 15, 953-960.

[7] Boustani M, Peterson B, Hanson L, Harris R, Lohr KN (2003) Screening for dementia in primary care: A summary of the evidence for the U.S. Preventive Services Task Force. Ann Intern Med 138, 927-937.

[8] Birks J, Flicker L (2006) Donepezil for mild cognitive impairment. Cochrane Database Syst Rev 3, Art No.: CD006104

[9] Boustani M, Jermoumi R (2012) Forecasting the future impact of early detection and management program for Alzheimer disease. In Dementia Care Research: Scientific Evidence,
Current Issues and Future Perspectives, Thyrian J, Hoffmann W, eds. Pabst Science Publishers, Lengerich/Westf., pp. 9-18.

[10] Teipel SJ, Ewers M, Reisig V, Schweikert B, Hampel H, Happich M (2007) Long-term cost-effectiveness of donepezil for the treatment of Alzheimer's disease. Eur Arch Psychiatry Clin Neurosci 257, 330-336.

[11] Boustani M, Callahan CM, Unverzagt FW, Austrom MG, Perkins AJ, Fultz BA, Hui SL, Hendrie HC (2005) Implementing a screening and diagnosis program for dementia in primary care. J Gen Intern Med 20, 572-577.

[12] Connolly A, Gaehl E, Martin H, Morris J, Purandare N (2011) Underdiagnosis of dementia in primary care: Variations in the observed prevalence and comparisons to the expected prevalence. Aging Ment Health 15, 978-984.

[13] Mitchell AJ, Meader N, Pentzek M (2011) Clinical recognition of dementia and cognitive impairment in primary care: A meta-analysis of physician accuracy. Acta Psychiatr Scand 124, 165-183.

[14] Löppönen M, Raiha I, Isoaho R, Vahlberg T, Kivela SL (2003) Diagnosing cognitive impairment and dementia in primary health care - a more active approach is needed. Age Ageing 32, 606-612.

[15] DGPPN and DGN (Deutsche Gesellschaft für Psychiatrie Psychotherapie und Nervenheilkunde and Deutsche Gesellschaft für Neurologie) (2009) S-3 Leitlinie "Demenzen". http://www.dgppn.de/fileadmin/user_upload/_medien/ download/pdf/kurzversion-leitlinien/s3-leitlinie-demenz-kf. pdf

[16] Vollmar HC, Mand P, Butzlaff M (2008) Demenz. DEGAM Leitlinie Nr. 12. Omicron Publishing, Düsseldorf.

[17] Kaduszkiewicz H, Wiese B, Steinmann S, Schon G, Hoffmann F, van den BH (2013) Diagnosing and diagnosis coding of dementias in claims data from German statutory health insurance. Psychiatr Prax. [Epub] doi: 10.1055/s-0033-1349505

[18] Thyrian JR, Fiss T, Dreier A, Böwing G, Angelow A, Lueke S, Teipel S, Flessa S, Grabe HJ, Freyberger HJ, Hoffmann W (2012) Life- and person-centred help in MecklenburgWestern Pomerania, Germany (DelpHi): Study protocol for a randomised controlled trial. Trial 13, 56.

[19] Calabrese P, Kessler J (2000) Screening for cognitive impairment in dementia - the DemTect procedure. Eur Neuropsychopharmacol 10(Suppl 3), 369.

[20] Thyrian JR, Hoffmann W (2012) Dementia care and general physicians-a survey on prevalence, means, attitudes and recommendations. Cent Eur J Public Health 20, 270-275.

[21] Eichler T, Thyrian JR, Dreier A, Wucherer D, Köhler L, Fiss T, Böwing G, Michalowsky B, Hoffmann W (2014) Dementia care management: Going new ways in ambulant dementia care within a GP-based randomized controlled intervention trial. Int Psychogeriatr 26, 247-256.

[22] Kessler J, Markowitsch HJ, Denzler P (1990) Mini-MentalStatus-Test (MMST) [German Version].

[23] Gauggel S, Birkner B (1999) Validity and reliability of a German version of the Geriatric Depression Scale (GDS). Zeitschrift fur Klinische Psychologie-Forschung und Praxis 28, 18-27.

[24] Yesavage JA, Brink TL, Rose TL, Lum O, Huang V, Adey M, Leirer VO (1982) Development and validation of a geriatric depression screening scale: A preliminary report. J Psychiatr Res 17, 37-49.

[25] Erzigkeit H, Lehfeld H, Pena-Casanova J, Bieber F, YekrangiHartmann C, Rupp M, Rappard F, Arnold K, Hindmarch I (2001) The Bayer-Activities of Daily Living Scale (B-ADL): Results from a validation study in three European countries. Dement Geriatr Cogn Disord 12, 348-358. 
[26] Hindmarch I, Lehfeld H, de JP, Erzigkeit H (1998) The Bayer Activities of Daily Living Scale (B-ADL). Dement Geriatr Cogn Disord 9(Suppl 2), 20-26.

[27] Breslow N, Day N (1980) Statistical Methods in Cancer Research, Vol 1. The analysis of case-control studies. (IARC Scientific Publication no. 32), International Agency for Research on Cancer, Lyon.

[28] Hosmer D, Lemeshow S, Sturdivant R(2013)Applied Logistic Regression, John Wiley \& Sons, New Jersey.

[29] Royston P, Sauerbrei W (2008) Multivariable Model-Building - A pragmatic approach to regression analysis based on fractional polynomials for continuous variables, John Wiley \& Sons, New York

[30] Rust KF, Rao JN (1996) Variance estimation for complex surveys using replication techniques. Stat Methods Med Res 5, 283-310.

[31] Stata Corp (2009) Stata Statistical Software: Release 11.

[32] Huber M, Kolzsch M, Rapp MA, Wulff I, Kalinowski S, Bolbrinker J, Hofmann W, Scholze J, Drager D, Kreutz R (2012) Antipsychotic drugs predominate in pharmacotherapy of nursing home residents with dementia. Pharmacopsychiatry 45, 182-188.

[33] Majic T, Pluta JP, Mell T, Aichberger MC, Treusch Y, Gutzmann H, Heinz A, Rapp MA (2010) The pharmacotherapy of neuropsychiatric symptoms of dementia: A cross-sectional study in 18 homes for the elderly in Berlin. Dtsch Arztebl Int 107, 320-327.

[34] Riedel-Heller SG, Schork A, Matschinger H, Angermeyer MC (1999) The role of referrals in diagnosing dementia at the primary care level. Int Psychogeriatr 11, 251-262.

[35] Qiu C, De RD, Fratiglioni L (2007) The epidemiology of the dementias: An update. Curr Opin Psychiatry 20, 380-385.
[36] Riedel-Heller SG, Schork A, Fromm N, Angermeyer MC (2000) [Dementia patients in general practice-results of a survey]. Z Gerontol Geriatr 33, 300-306.

[37] Borson S, Scanlan J, Hummel J, Gibbs K, Lessig M, Zuhr E (2007) Implementing routine cognitive screening of older adults in primary care: Process and impact on physician behavior. J Gen Intern Med 22, 811-817.

[38] Riedel-Heller SG, Busse A, Aurich C, Matschinger H, Angermeyer MC (2001) Prevalence of dementia according to DSM-III-R and ICD-10: Results of the Leipzig Longitudinal Study of the Aged (LEILA75+) Part 1. Br J Psychiatry 179, 250-254.

[39] Kalbe E, Kessler J, Calabrese P, Smith R, Passmore AP, Brand M, Bullock R (2004) DemTect: A new, sensitive cognitive screening test to support the diagnosis of mild cognitive impairment and early dementia. Int J Geriatr Psychiatry 19, 136-143.

[40] Kohn N, Kalbe E, Georg H, Kessler J (2007) Vergleich MMST und DemTect: Spezifität und Sensitivität bei primär kognitiven Störungen. Akt Neurol 34, P672.

[41] Mackin RS, Ayalon L, Feliciano L, Arean PA (2010) The sensitivity and specificity of cognitive screening instruments to detect cognitive impairment in older adults with severe psychiatric illness. J Geriatr Psychiatry Neurol 23, 94-99.

[42] Le Couteur DG, Doust J, Creasey H, Brayne C (2013) Political drive to screen for pre-dementia: Not evidence based and ignores the harms of diagnosis. BMJ 347, f5125.

[43] Brunet MD, McCartney M, Heath I, Tomlinson J, Gordon P, Cosgrove J, Deveson P, Gordon S, Marciano SA, Colvin D, Sayer M, Silverman R, Bhattia N (2012) There is no evidence base for proposed dementia screening. BMJ 345, e8588. 